www.jmscr.igmpublication.org

Impact Factor (SJIF): 6.379

Index Copernicus Value: 79.54

ISSN (e)-2347-176x ISSN (p) 2455-0450

crossrefDOI: https://dx.doi.org/10.18535/jmscr/v6i11.31

Journal Of Medical Science And Clinical Research

IGM Publication

An Official Publication of IGM Publication

\title{
Case Study of Clinical Profile and Outcome of Rodenticide Poisoning
}

\author{
Authors \\ Dr Sakthi Vignesh $D^{1}$, Dr Aswinth $R^{2^{*}}$, Dr Sudharsan $S^{3}$, Dr Subathra $C^{4}$ \\ ${ }^{1,4}$ Post Graduate, Department of Medicine, Rajah Muthiah Medical College and Hospital \\ ${ }^{2}$ Lecturer, Department of Medicine, Rajah Muthiah Medical College and Hospital \\ ${ }^{3}$ Professor, Department of Medicine, Rajah Muthiah Medical College and Hospital \\ *Corresponding Author
}

Dr Aswinth R

Email: aswinth.r@gmail.com

\begin{abstract}
Introduction: Rodenticide poisoning is the second most common cause of poisoning in our area next to $O P C$ poisoning. It may be due to easy availability in local shops and markets and low price of the poison. Rodenticide can cause increased morbidity and mortality when compared to other poisons. The management includes conservative measures with serial monitoring of liver and renal parameters.

Materials and Methods: It is a prospective study of rodenticide poisoning case admitted to our hospital between the study periods of 1, January 2017 to 31, May 2018. All patients aged above 13 years, of both sexes were included in the study. The demographic profile, clinical symptoms and signs, investigation details, complications and outcome were noted.

Results: A total of 255 cases presented with acute consumption of rodenticide during the study. The majority were within the age group of 20-30 year age group and mostly married (62.7\%). Most patients had gastrointestinal manifestations such as acute hepatic failure followed by bleeding diathesis. Complications were seen in $39.2 \%$ of the study population and death occurred in $2.7 \%$ of the cases.

Conclusion: The most toxic rat killer poisons with high mortality are yellow phosphorus followed by zinc phosphide. No specific antidote has been approved for the management of this poisoning. Hence, early initiation of first aid and good supportive care plays a major role for a better outcome. Also, tattoos and self-inflicted wounds can be used to predict the presence of underlying psychiatric disturbance among these patients.
\end{abstract}

Keywords: Rodenticide poisoning, Outcome, Tattoo, Psychological correlation.

\section{Introduction}

Poisoning forms the major share of emergency health care and about one-third of ICU admissions in rural India. In 1990, Jeyaratnam ${ }^{1}$ estimated that self-harm resulted in 2 million cases of poisoning each year with 200000 deaths. In contrast, accidental and occupational exposure were estimated to cause 1 million cases with 20000 deaths ${ }^{1}$. Studies have shown that deliberate self-poisoning has a far higher mortality than accidental poisoning., ${ }^{2,3}$

Among poisoning, in our region, next to organophosphorus poisoning, rat killer or rodenticide poisoning remains the second most 
common ingested poison. Rodenticides are a common entity, available in almost every household due to its cheap and easy availability in the markets. Since they are designed to kill mammals, they are also toxic to humans. Almost every system is affected in rodenticide poisoning and also there are no definite treatment guidelines available. Rodenticide toxicity can range from asymptomatic presentation to life - threatening complications and death. Commonly available rodenticides in our area were yellow phosphorus (paste), zinc phosphide (powder), and bromadiolone (cake). The clinical profile and outcome of these compounds have been briefly discussed in our study. Interestingly in our study, the incidence of tattoo or self- inflicted wounds were more in cases of rodenticide poison when compared to other poison cases such as organophosphorus. Hence special attention is givento those cases for psychological evaluation.

\section{Materials and Methods}

This is a prospective observational study conducted in the Department of Medicine, Rajah Muthiah Medical College \& Hospital, Chidambaram. This study included all patients above the age of 13 years, of both sexes, admitted with a history of consumption of rodenticide from 1, January 2017 to 31, May 2018.

A complete history, detailed clinical examination related to the toxicity of the compound and the relevant biochemical investigations were performed

The patient was followed until their stay in the hospital. They are noticed for development of complications or further prognosis of the patient and relevant investigation data are collected and the outcome was assessed.

\section{Inclusion Criteria}

- All patients of both sexes admitted with history consumption of rodenticide poisoning

- Suicidal and accidental poisoning

- Age > 12 years

\section{Exclusion Criteria}

- Patients who consumed rodenticide poison along with any other poison.

- Patients with a history of liver disease

- Patient with a history of bleeding disorders

- Patients on medications like anticoagulants, antiplatelet drugs

- Age $<12$ years

\section{Statistical analysis}

Datas were entered into Microsoft excel data sheet and was analyzed using SPSS 22 version software. Categorical data was represented in the form of Frequencies and proportions.

\section{Results}

A total of 255 patients with rodenticide poisoning were admitted during the study period of 1 , January 2017- 31, May 2018 and were taken up for study.

Table 1: Age Distribution

\begin{tabular}{|l|c|c|}
\hline Age group (years) & No. of patients & \% \\
\hline $13-19$ & 52 & 20.3 \\
\hline $20-30$ & 119 & 46.7 \\
\hline $31-50$ & 68 & 26.7 \\
\hline$>50$ & 16 & 6.3 \\
\hline Total & 255 & 100 \\
\hline
\end{tabular}

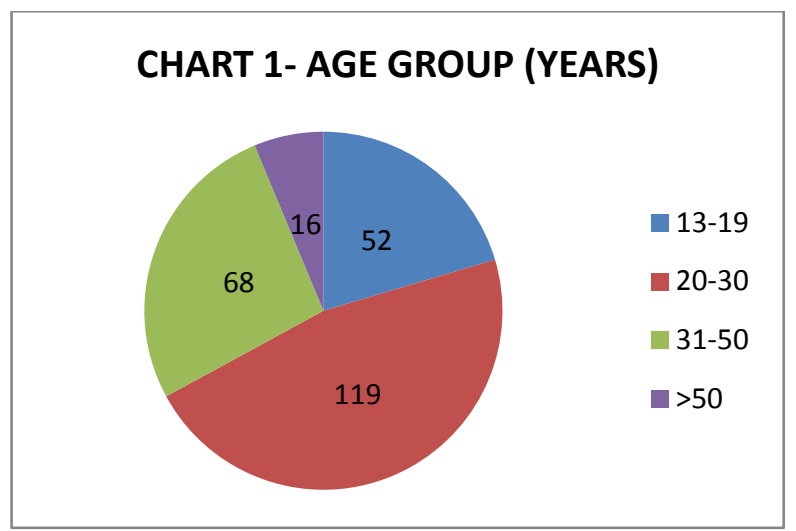

Majority of the subjects were in the age group 2030 years $(46.7 \%)$, followed by $31-50$ years (26.7\%), 20.3\% were in the age group 13-19 years, $6.3 \%$ were in the age group $>50$ years.

Table 2: Gender Distribution

\begin{tabular}{|l|c|c|c|c|}
\hline \multirow{2}{*}{ Gender } & \multicolumn{2}{|c|}{ Married } & \multicolumn{2}{c|}{ Unmarried } \\
\cline { 2 - 5 } & $\mathbf{N}$ & $\mathbf{\%}$ & $\mathbf{N}$ & $\mathbf{\%}$ \\
\hline Male & 71 & 55.1 & 58 & 44.9 \\
\hline Female & 89 & 70.6 & 37 & 29.4 \\
\hline Total & 160 & 62.7 & 95 & 37.3 \\
\hline
\end{tabular}




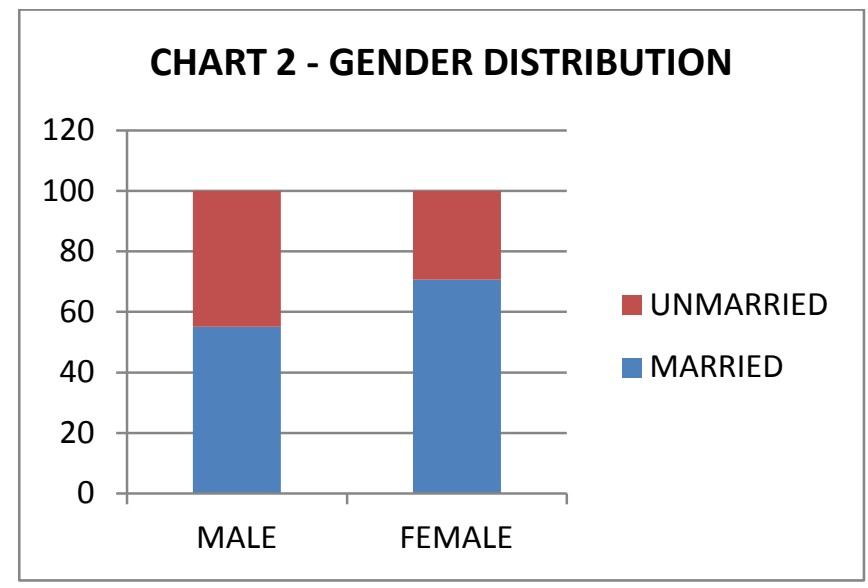

In our study, the ratio of male and female were almost equal. The incidence of rodenticide poisoning was more common among the married $(62.7 \%)$. This may be due to their high marital stress.

Table 3: Socio Economic Status Distribution

\begin{tabular}{|l|c|c|}
\hline SES & No. of patients & \% \\
\hline Upper & 1 & 0.4 \\
\hline Upper middle & 51 & 20 \\
\hline Lower middle & 159 & 62.3 \\
\hline Upper lower & 44 & 17.3 \\
\hline Lower & 0 & 0 \\
\hline
\end{tabular}

CHART 3 - SOCIOECONOMIC STATUS

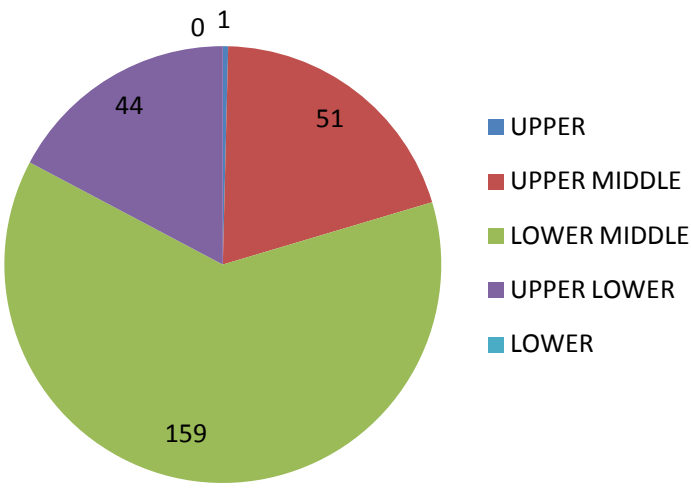

In our study, according to Modified Kuppusamy socioeconomic scale, $62.3 \%$ of the study population belonged to lower middle class, followed by $17.3 \%$ in upper lower class.

Table 4: Type of rodenticide consumed

\begin{tabular}{|l|c|c|}
\hline Rodenticide type & No. of patients & \% \\
\hline Yellow phosphorus & 159 & 62.3 \\
\hline Zinc phosphide & 70 & 27.5 \\
\hline Bromadiolone & 25 & 9.8 \\
\hline Others & 1 & 0.4 \\
\hline Total & 255 & 100 \\
\hline
\end{tabular}

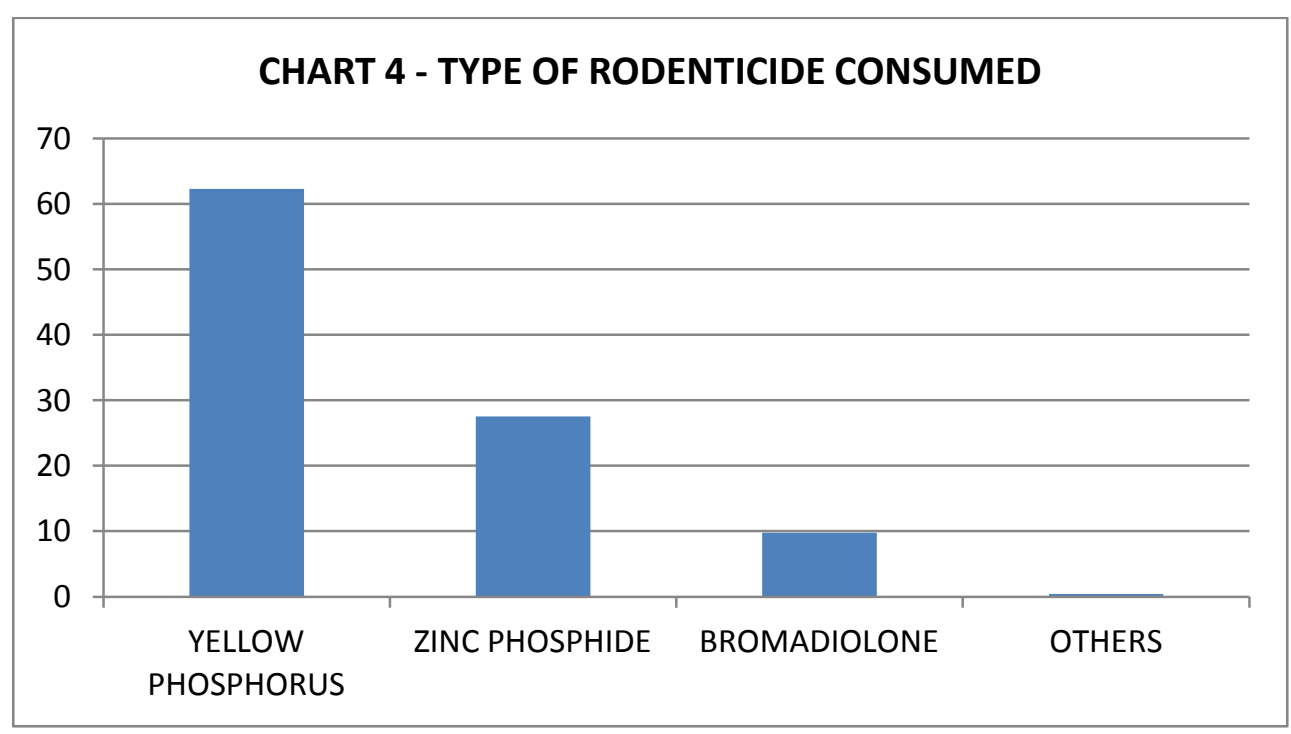

In our study, most of the patients $(62.3 \%)$ consumed yellow phosphorus, followed by zinc phosphide (27.5\%), bromadiolone (9.8\%), and others $(0.4 \%)$. 
Table 5: Clinical Features on Presentation - each compound

\begin{tabular}{|l|c|c|c|c|c|c|}
\hline \multirow{2}{*}{ Clinical features } & \multicolumn{2}{|c|}{ Yellow phosphorus } & \multicolumn{2}{c|}{ Zinc phosphide } & \multicolumn{2}{c|}{ Bromadiolone } \\
\cline { 2 - 7 } & $\mathbf{N}$ & $\mathbf{\%}$ & $\mathbf{N}$ & $\mathbf{\%}$ & $\mathbf{N}$ & $\mathbf{\%}$ \\
\hline Vomiting & 76 & 47.5 & 46 & 65.7 & 12 & 48 \\
\hline Abdominal pain & 75 & 46.9 & 21 & 30 & 0 & 0 \\
\hline Giddiness & 18 & 11.3 & 11 & 15.7 & 3 & 12 \\
\hline Headache & 14 & 8.6 & 0 & 0 & 0 & 0 \\
\hline Chest pain & 8 & 5 & 0 & 0 & 4 & 16 \\
\hline Icterus & 11 & 6.9 & 0 & 0 & 0 & 0 \\
\hline Bleeding & 10 & 6.3 & 0 & 0 & 0 & 0 \\
\hline Diarrhoea & 7 & 4.4 & 0 & 0 & 0 & 0 \\
\hline Thirst & 7 & 4.4 & 0 & 0 & 0 & 0 \\
\hline
\end{tabular}

Chart 5: Clinical features on presentation

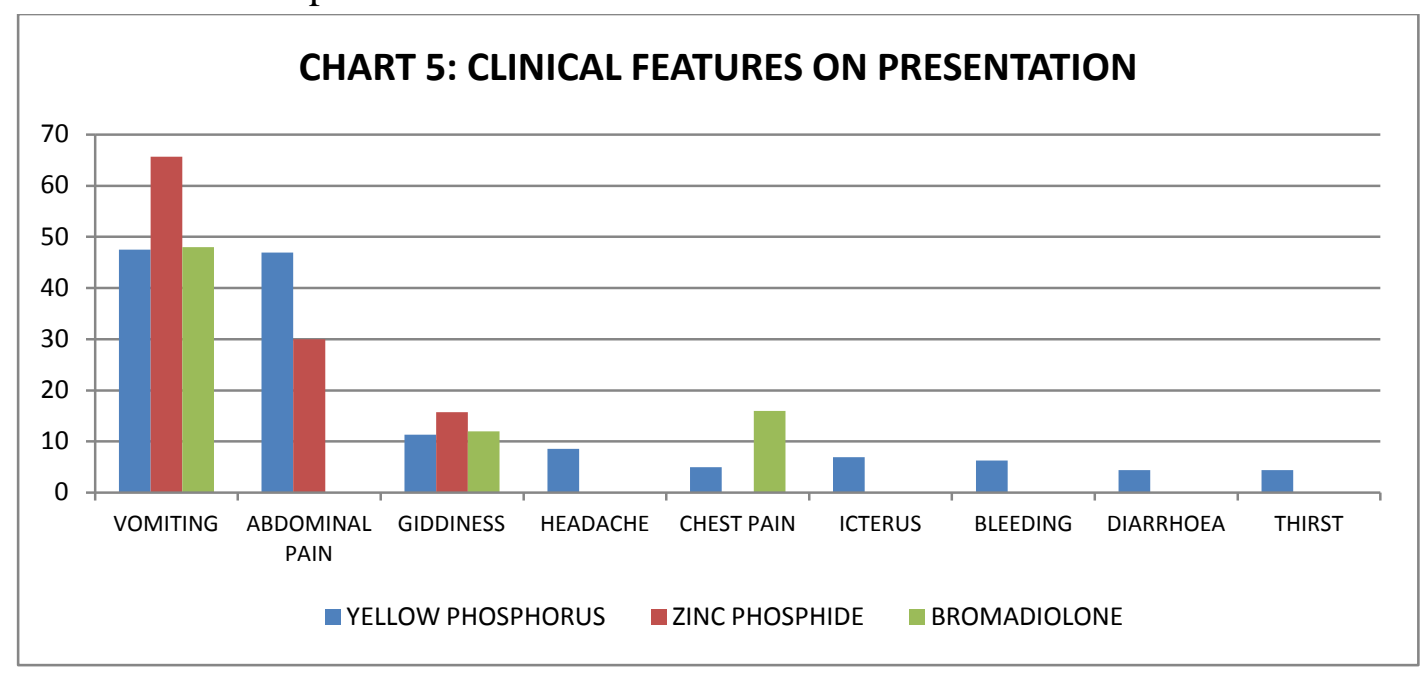

In this study, most of the patients had vomiting and abdominal pain. Also, giddiness, headache, diarrhoea and thirst were present in a notable number of patients.

Table 6: Lab investigations on admission

\begin{tabular}{|l|c|c|c|c|c|c|}
\hline \multirow{2}{*}{ Lab parameters } & \multicolumn{2}{|c|}{ Yellow phosphorus } & \multicolumn{2}{c|}{ Zinc phosphide } & \multicolumn{2}{c|}{ Bromadiolone } \\
\cline { 2 - 7 } & $\mathbf{N}$ & $\mathbf{\%}$ & $\mathbf{N}$ & $\mathbf{\%}$ & $\mathbf{N}$ & $\mathbf{\%}$ \\
\hline INR $>1.1$ & 84 & 52.5 & 44 & 62.8 & 8 & 32 \\
\hline Total bilirubin $>2.5$ & 12 & 7.5 & 0 & 0 & 0 & 0 \\
\hline SGPT $>40$ & 41 & 25.6 & 20 & 28.6 & 0 & 0 \\
\hline
\end{tabular}

On admission, patients consumed all types of rodenticide had significant elevation in INR. Elevated bilirubin present in around $25 \%$ of those who consumed yellow phosphorus and zinc phosphide.

CHART 6 - LAB PARAMETERS ON ADMISSION

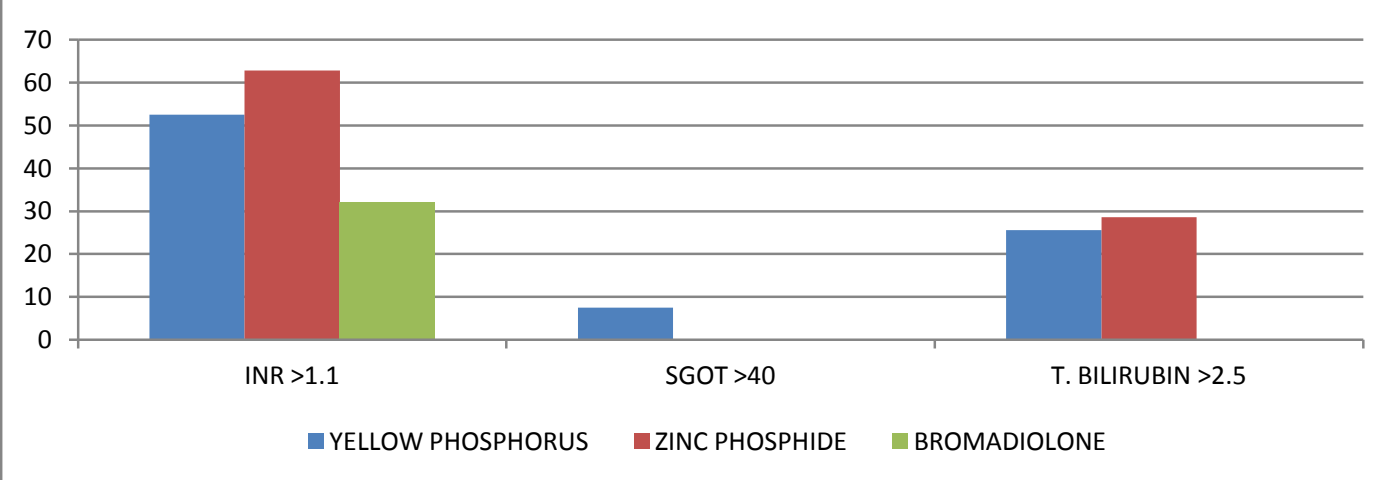


Table 7: Lab investigations on day 4

\begin{tabular}{|l|c|c|c|c|c|c|}
\hline \multirow{2}{*}{ Lab parameters } & \multicolumn{2}{|c|}{ Yellow phosphorus } & \multicolumn{2}{c|}{ Zinc phosphide } & \multicolumn{2}{c|}{ Bromadiolone } \\
\cline { 2 - 7 } & $\mathbf{N}$ & $\mathbf{\%}$ & $\mathbf{N}$ & $\mathbf{\%}$ & $\mathbf{N}$ & $\mathbf{\%}$ \\
\hline INR $>1.1$ & 88 & 55 & 44 & 62.9 & 19 & 76 \\
\hline Total bilirubin $>2.5$ & 19 & 11.9 & 3 & 4.3 & 0 & 0 \\
\hline SGPT $>40$ & 52 & 35.9 & 20 & 30.3 & 0 & 0 \\
\hline
\end{tabular}

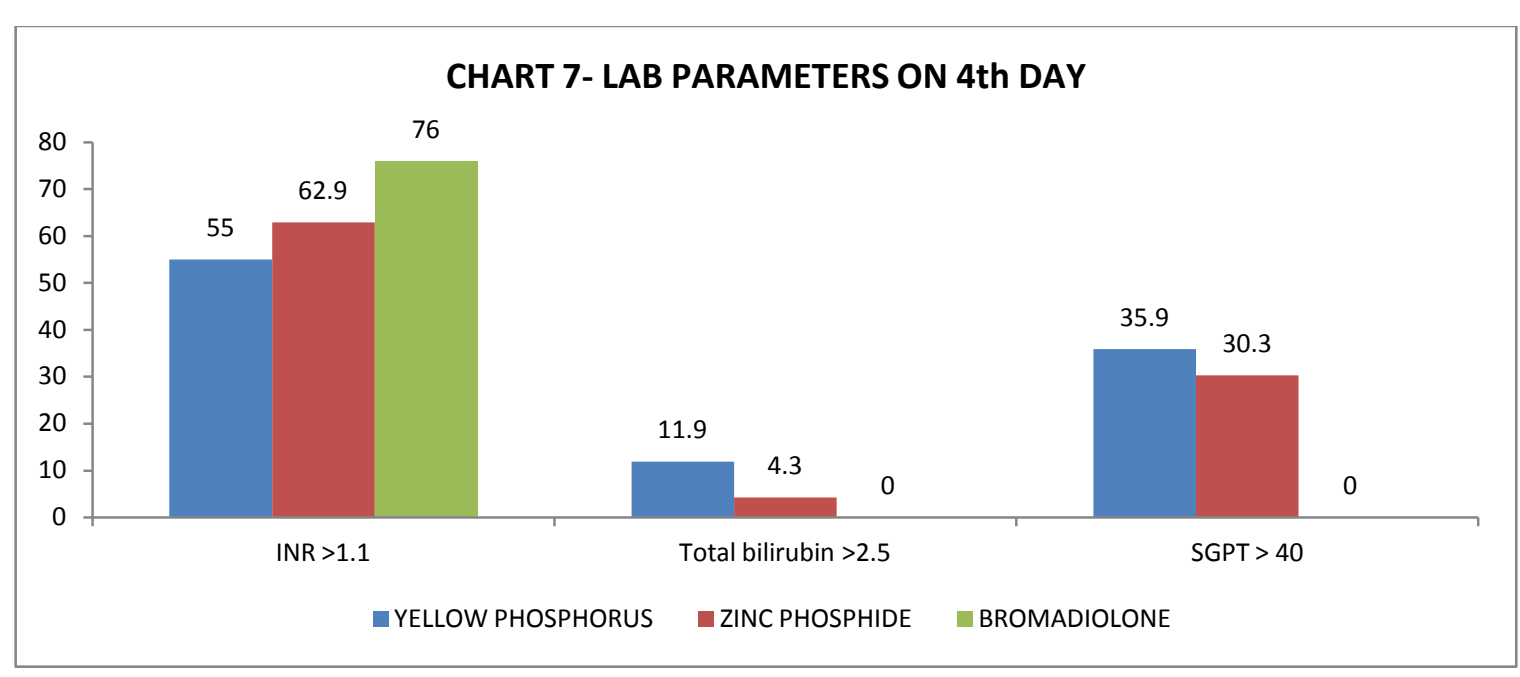

On day 4, a significant elevation in INR noted after consumption of all types of rodenticides. $30 \%$ of the patients who consumed yellow phosphorus and zinc phosphide had elevated liver enzymes.

Table 8: Vitals on presentation

\begin{tabular}{|l|c|c|}
\hline Vitals & N & \% \\
\hline Bradycardia & 25 & 9.8 \\
\hline Hypotension & 4 & 1.6 \\
\hline Hypoglycaemia & 42 & 16.4 \\
\hline
\end{tabular}

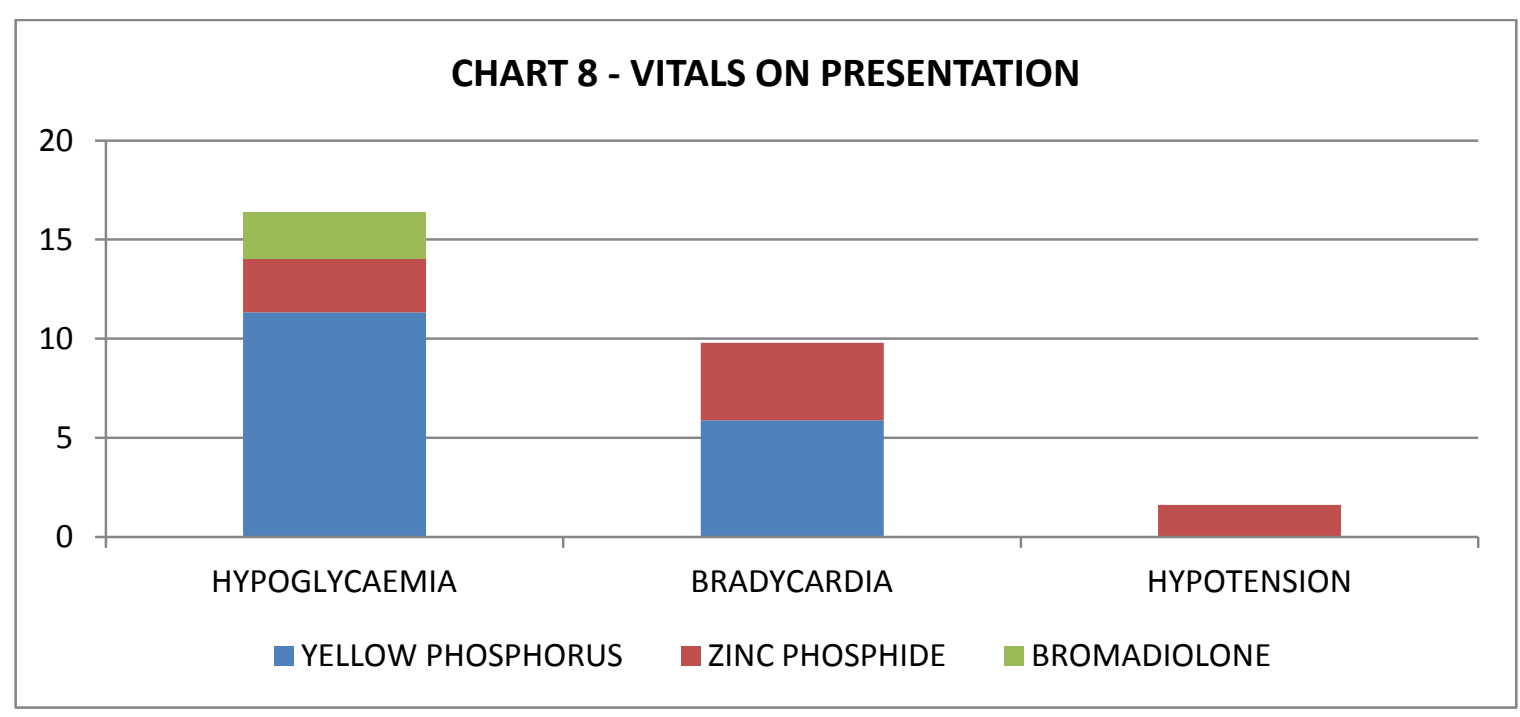

On admission, 16\% had hypoglycaemia, 9.8\% had bradycardia, 4 patients who consumed zinc phosphide had hypotension. 
Table 9: Complication of each compound

\begin{tabular}{|l|c|c|c|c|c|c|}
\hline \multirow{2}{*}{ Complication } & \multicolumn{2}{|c|}{ Yellow phosphorus } & \multicolumn{2}{c|}{ Zinc phosphide } & \multicolumn{2}{c|}{ Bromadiolone } \\
\cline { 2 - 7 } & $\mathbf{N}$ & $\mathbf{\%}$ & $\mathbf{N}$ & $\mathbf{\%}$ & $\mathbf{N}$ & $\mathbf{\%}$ \\
\hline Raised INR without haemorrhage & 74 & 46.25 & 44 & 62.9 & 11 & 44 \\
\hline Raised INR with hemorrhage & 10 & 6.25 & 0 & 0 & 0 & 0 \\
\hline Hepatitis & 41 & 25.63 & 20 & 28.6 & 0 & 0 \\
\hline Hepatic encephalopathy & 4 & 2.5 & 0 & 0 & 0 & 0 \\
\hline Myocarditis & 2 & 1.25 & 1 & 1.4 & 0 & 0 \\
\hline
\end{tabular}

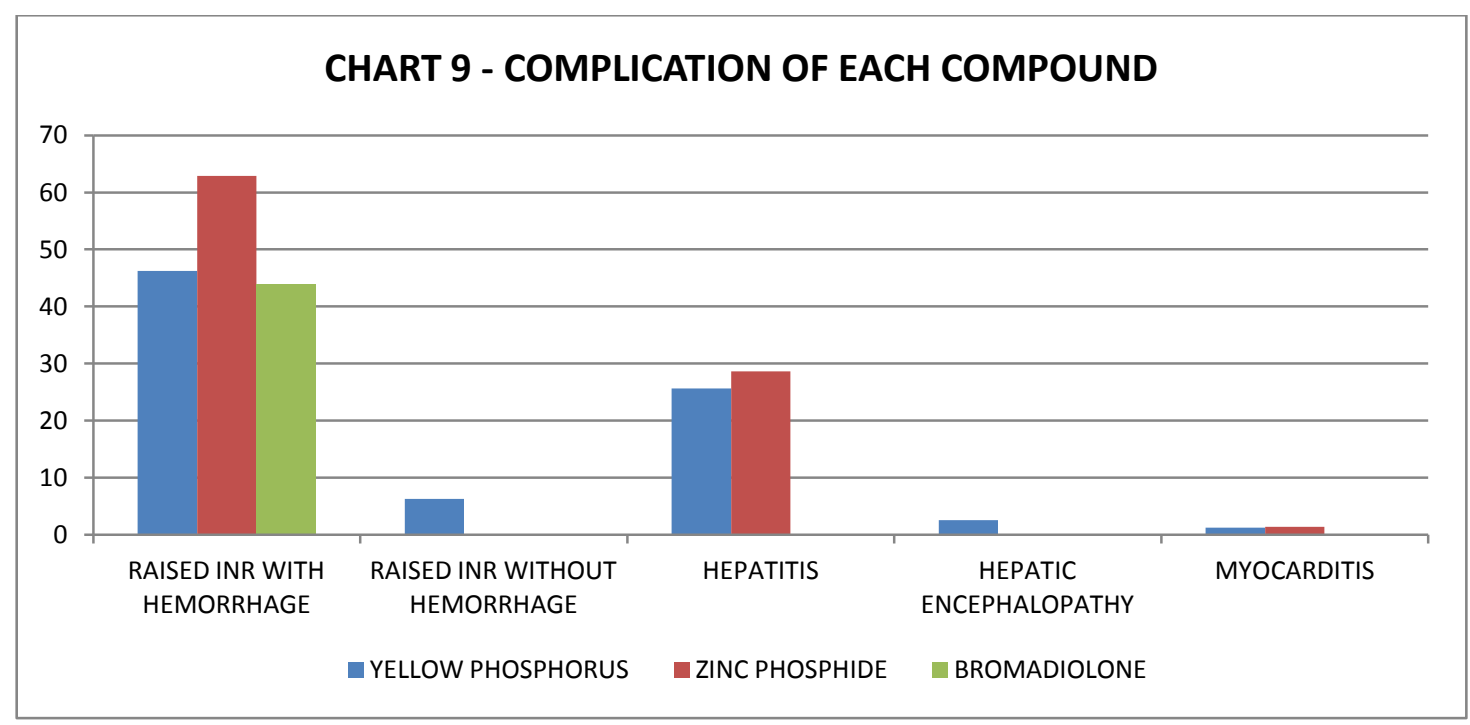

Most of the patients recovered without any major complication. 10 patients had raised INR with haemorrhage, 61 patients had hepatitis, 4 patients had hepatic encephalopathy, 2 patients had myocarditis.

Table 10 Outcome in each type of rodenticide

\begin{tabular}{|l|c|c|c|c|c|c|c|c|}
\hline \multirow{2}{*}{ Rodenticide type } & $\begin{array}{c}\text { Recovered without } \\
\text { complication }\end{array}$ & \multicolumn{2}{c|}{$\begin{array}{c}\text { Recovered with } \\
\text { complication }\end{array}$} & \multicolumn{2}{c|}{ Referred } & \multicolumn{2}{c|}{ Expired } \\
\cline { 2 - 10 } & $\mathbf{N}$ & $\mathbf{\%}$ & $\mathbf{N}$ & $\mathbf{\%}$ & $\mathbf{N}$ & $\mathbf{\%}$ & $\mathbf{N}$ & $\mathbf{\%}$ \\
\hline Yellow phosphorus & 89 & 55.3 & 21 & 13.2 & 43 & 27.1 & 7 & 4.4 \\
\hline Zinc phosphide & 40 & 57.1 & 21 & 30 & 9 & 12.9 & 0 & 0 \\
\hline Bromadiolone & 19 & 76 & 3 & 12 & 3 & 12 & 0 & 0 \\
\hline Total & 148 & 58.1 & 45 & 17.6 & 55 & 21.6 & 7 & 2.7 \\
\hline
\end{tabular}

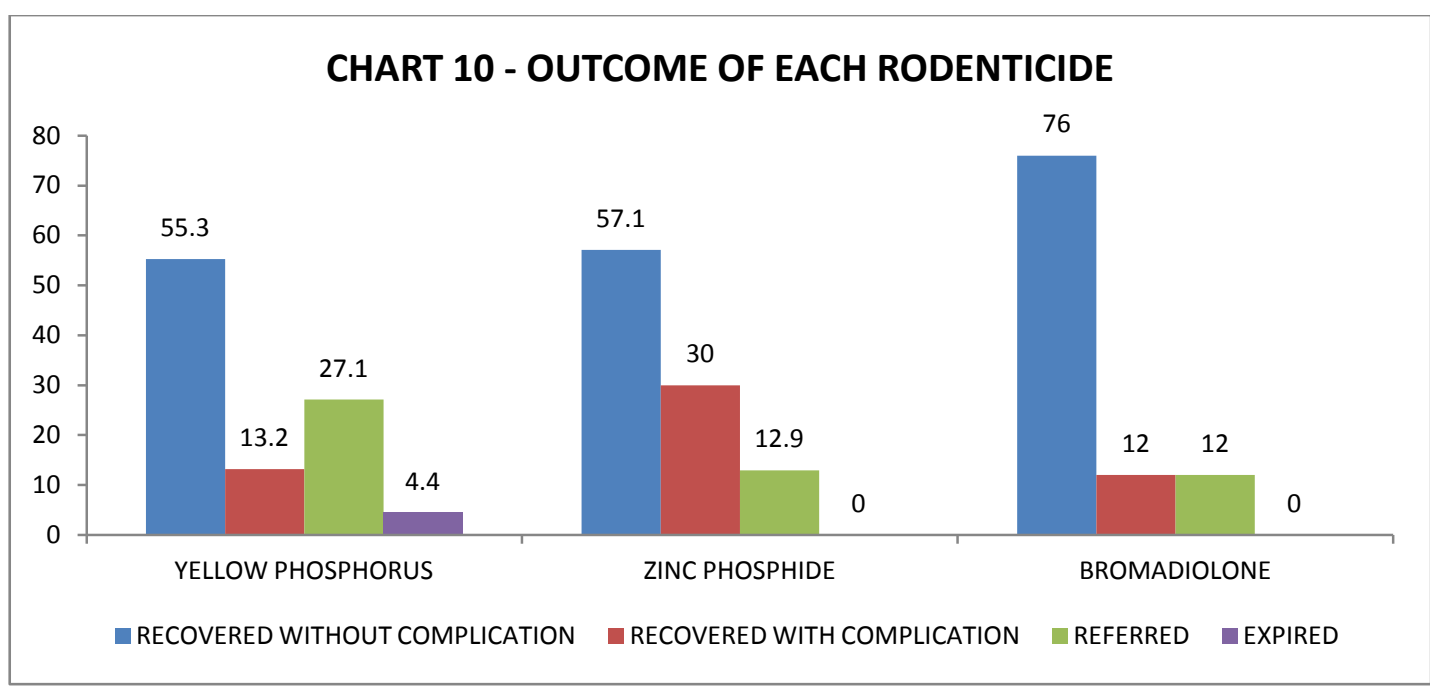

$58 \%$ of the patients recovered without complication, $17 \%$ recovered with complication, $21 \%$ were referred and $2.7 \%$ (7 patients) expired. 
Table 11: Psychiatric opinion of patients consumed rodenticide poison

\begin{tabular}{|l|c|}
\hline Psychiatric opinion & No. of patients \\
\hline Adjustment disorder & 18 \\
\hline Adjustment disorder with deliberate self-harm & 73 \\
\hline Deliberate self-harm & 16 \\
\hline Brief depressive episodes & 21 \\
\hline Intrapersonal conflict & 19 \\
\hline Alcohol dependent syndrome with abstinence & 5 \\
\hline Alcohol intoxication and alcohol harmful use & 11 \\
\hline Cluster B traits & 4 \\
\hline
\end{tabular}

Out of 189 patients, for whom psychiatric opinion was obtained, $88 \%$ were diagnosed with a psychiatric disorder.

Table 12: Tattoo and self-inflicted wounds in cases of rodenticide poisoning

\begin{tabular}{|l|c|c|}
\hline Tattoo \& self- inflicted wounds & $\mathbf{N}$ & $\mathbf{\%}$ \\
\hline MALE & 74 & 57.4 \\
\hline FEMALE & 11 & 8.7 \\
\hline
\end{tabular}

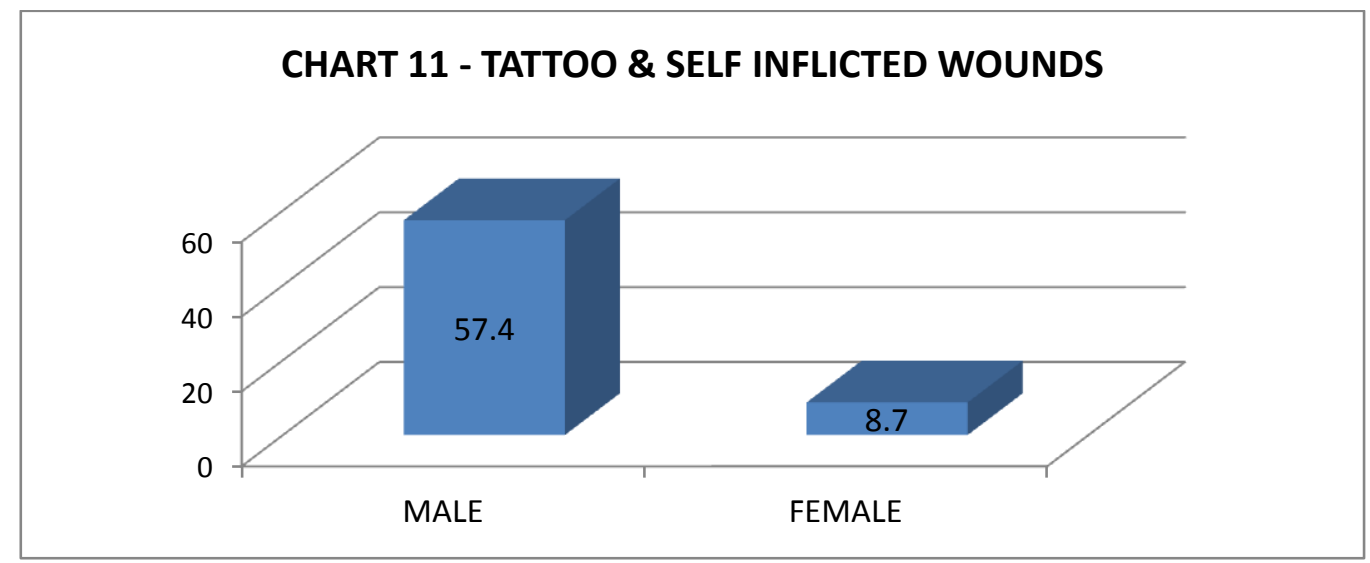

In our study, a total of 85 patients had self-inflicted wounds or tattoo pierced in their forearm or chest. Majority of them were male (74 patients).

Table 13: Tattoos and their psychological correlation

\begin{tabular}{|l|c|c|}
\hline Psychiatric outcome & N & \% \\
\hline Deliberate self-harm & 44 & 51.8 \\
\hline Adjustment disorder & 42 & 49.4 \\
\hline Cluster B traits & 4 & 4.7 \\
\hline Depression & 5 & 5.9 \\
\hline
\end{tabular}

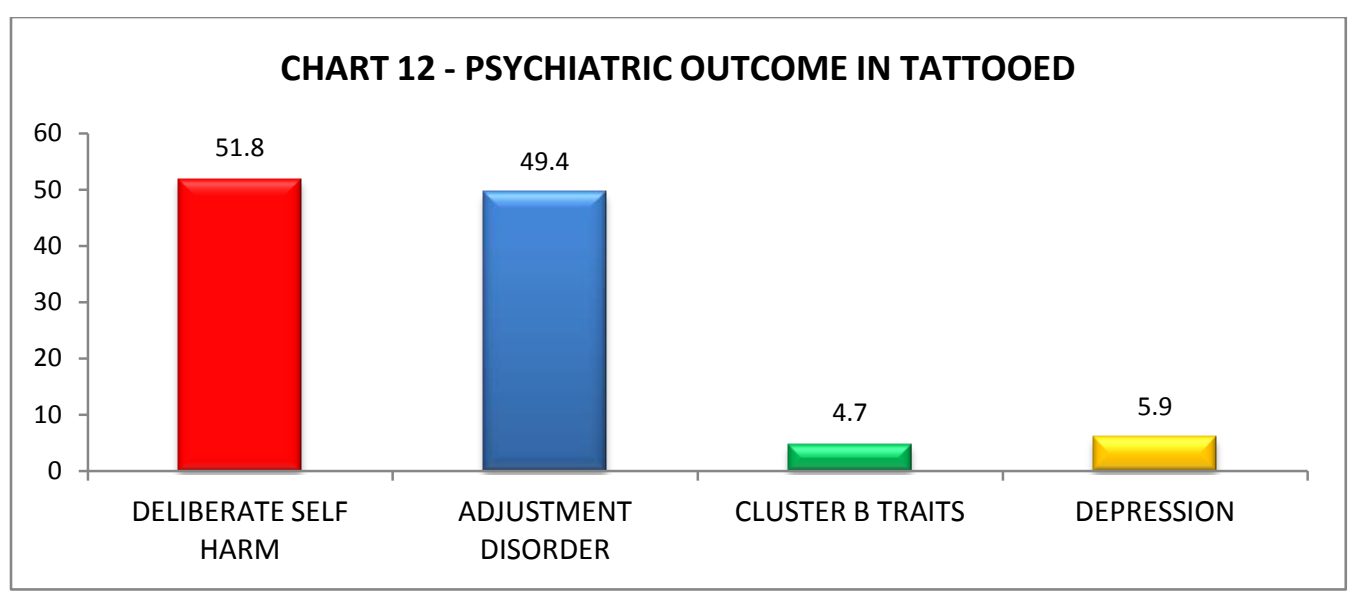


Of those tattooed and consumed rodenticide poison, 42 (49.4\%) patients were diagnosed to have adjustment disorder, $44(51.8 \%)$ patients were diagnosed to have intentions for deliberate self-harm, 4 (4.7\%) patients were diagnosed to have Cluster B traits, 5 (5.9\%) patients had depression.

Table 14: Different tattoos observed in our study

\begin{tabular}{|l|c|c|}
\hline Tattoo category & N & \% \\
\hline Identification tattoo & 8 & 9.4 \\
\hline Religious & 4 & 4.7 \\
\hline Symbols & 10 & 11.8 \\
\hline Love & 36 & 42.4 \\
\hline Animals & 10 & 11.8 \\
\hline Self-inflicted wounds & 16 & 18.8 \\
\hline
\end{tabular}

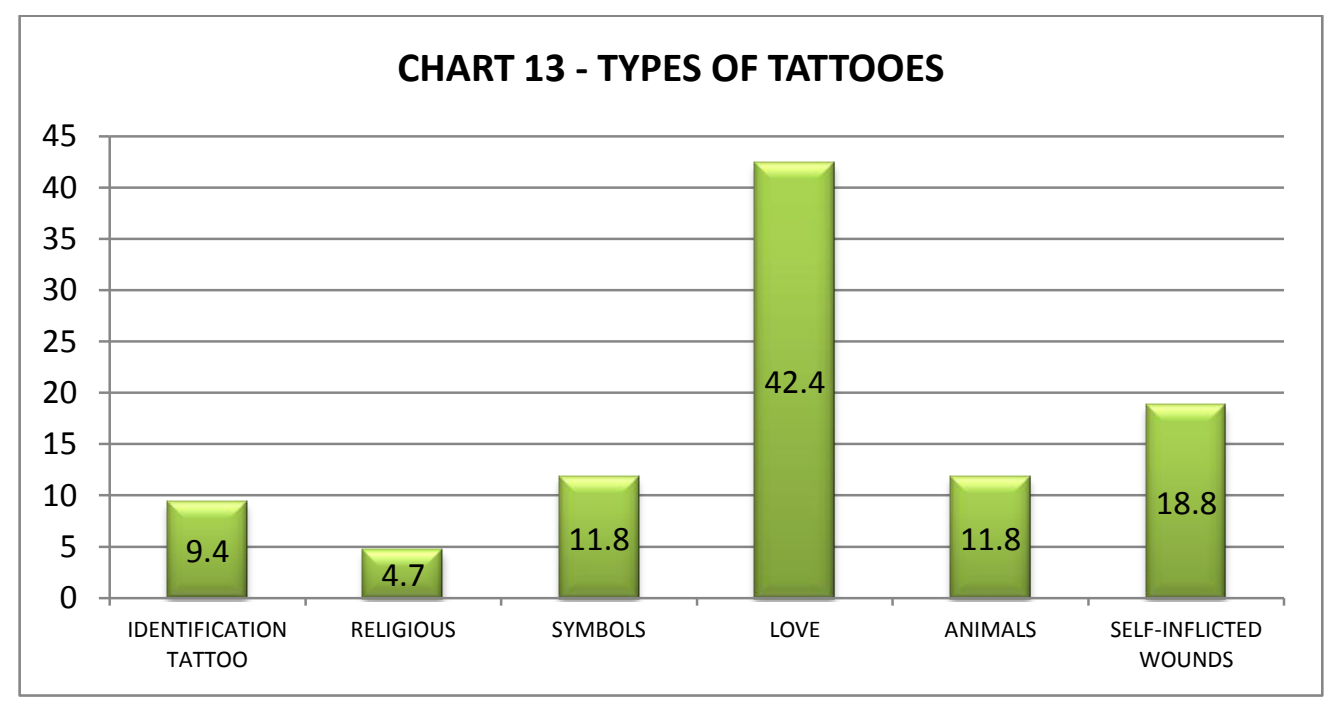

In our study, the common type of tattoo encountered was love tattoos $(42.4 \%)$, followed by self-inflicted wounds (18.8\%). $11.8 \%$ each had tattoos of animals and symbols. $9.4 \%$ had identification tattoos. $4.7 \%$ had religious tattoos.

\section{Some of the tattoos observed in our study}

\section{Identification tattoos}

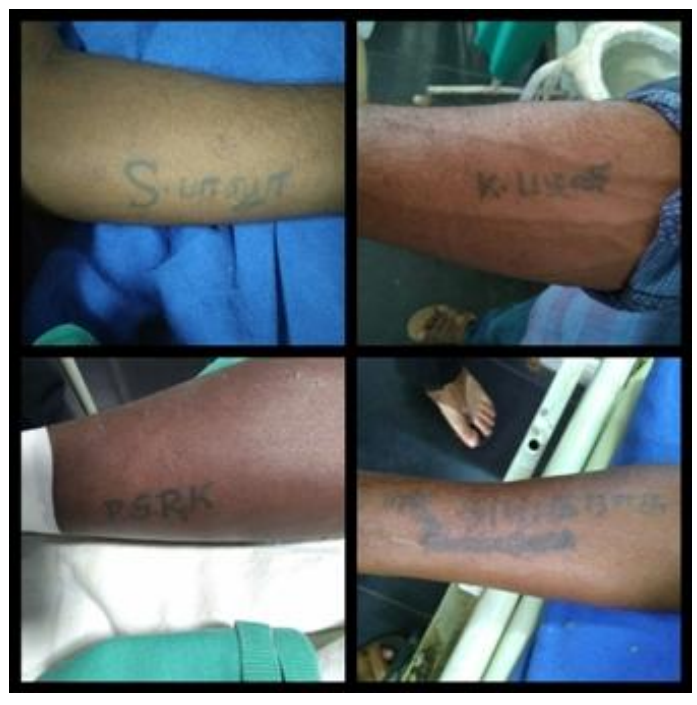

\section{Love tattoos}

Most of the male patients had either their mother name or their lover name inscribed on their forearms or chest.

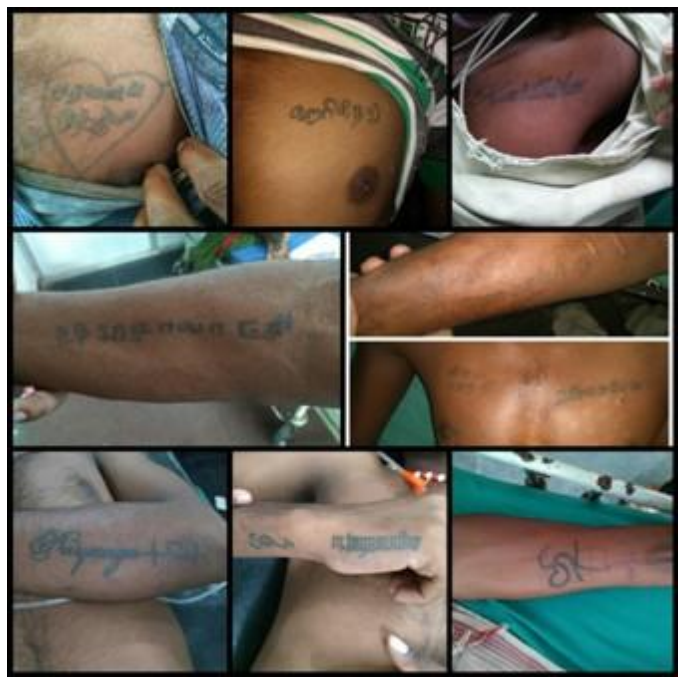

\section{Religious tattoos}

Religious inscriptions such as Om, Jesus-cross, Lord Shiva were inscribed in some individuals. 


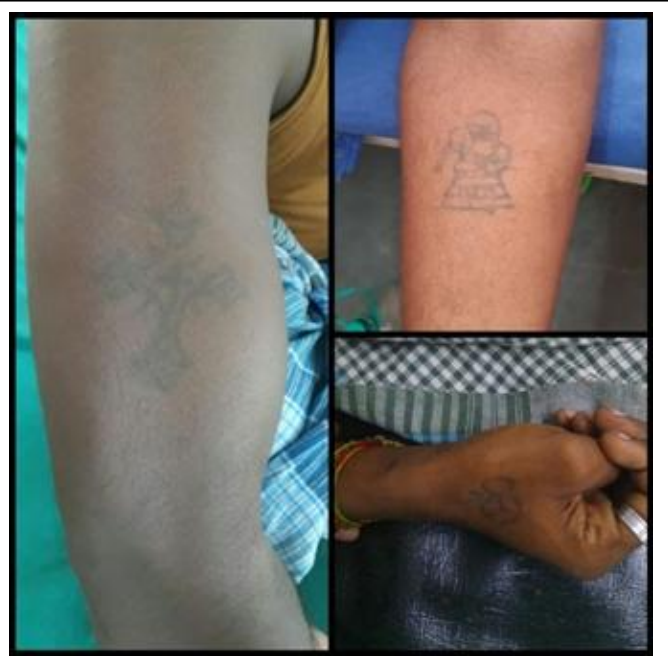

\section{Symbols}

Most females had general symbols inscribed in their forearm.

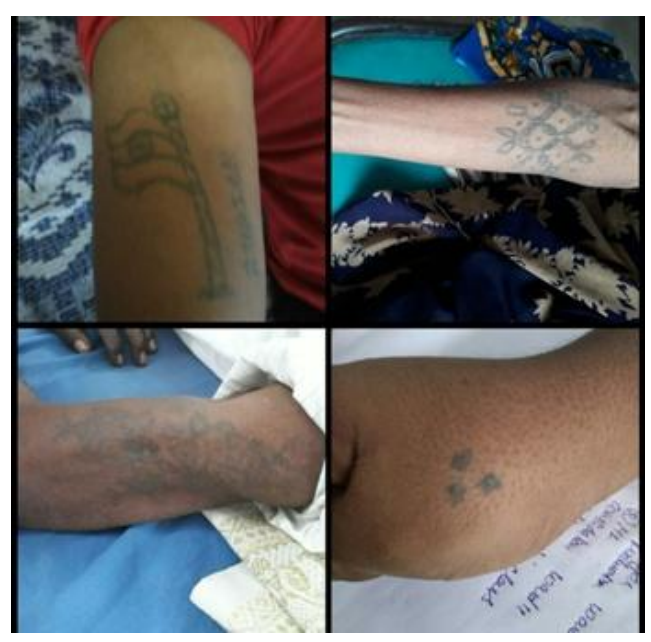

\section{Animals}

Creatures such as scorpion, dragon, tiger, lion, etc were inscribed in the forearm, mostly in males.

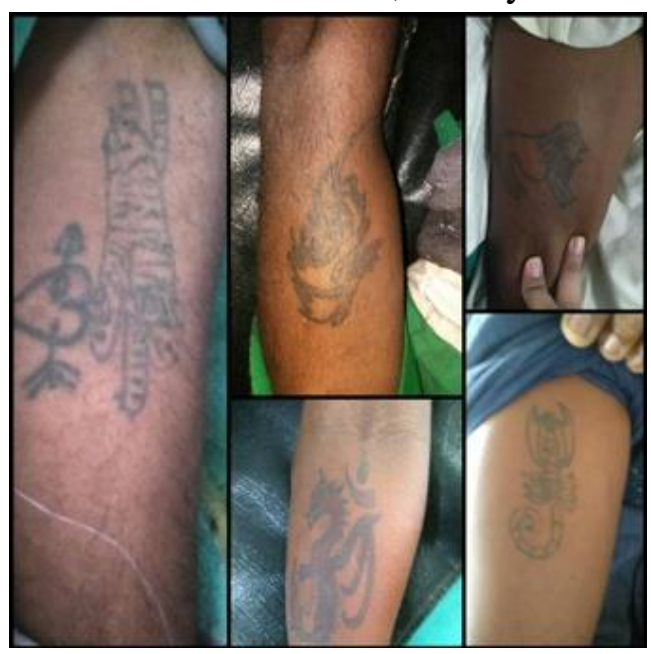

\section{Self-inflicted wounds}

Self-inflicted wounds such as cigarette butt marks, tentative cuts and burns were present in the individual's forearms, both in males and females.

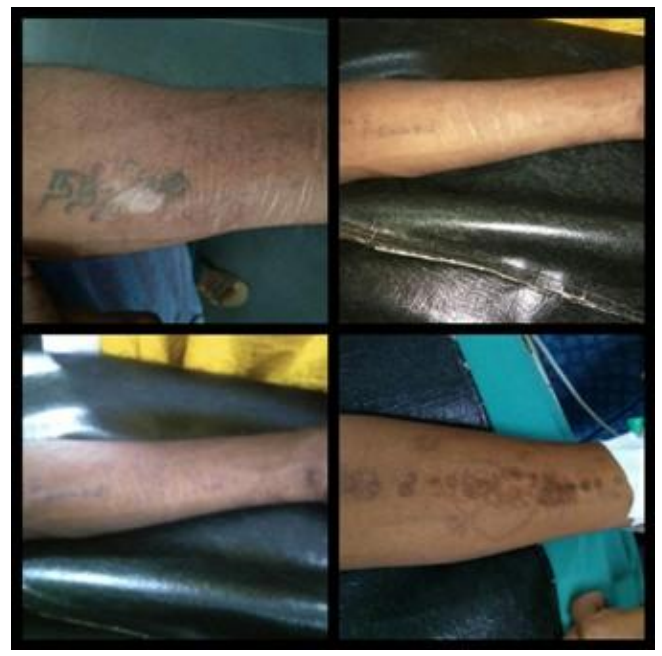

\section{Discussion}

In the study in our area, most of the patients ingested yellow phosphorus (62.3\%), followed by zinc phosphide (27.5\%), and bromadiolone $(9.8 \%)$.

This is comparable to the study done by Govindamurugan $^{4}$ et al in Thanjavur medical college, where $70 \%$ were yellow phosphorus, $18 \%$ were zinc phosphide, and $11 \%$ were warfarin. In a study by Nalabothu ${ }^{5} \mathrm{M}$ et al in Kasturbha College, Manipal 44\% were yellow phosphorus, 33\% were phosphides, and $21 \%$ were warfarin.

This study was in contrast to the study conducted by Arunkumar ${ }^{6}$ et al in Stanley medical college, were $55.8 \%$ were zinc phosphide, $39.3 \%$ were bromadiolones, $2.6 \%$ were yellow phosphorus.

In this study, the incidence of poisoning in males and females were almost equal (1.02:1). Incidences were more in the married group (62.7\%), probably due to increased marital stress.

Most of the patient who consumed poison was in the age group of $20-30$ years $(46.7 \%)$. This is comparable to a study by Arunkumar et $\mathrm{al}^{6}$, were $49.5 \%$ were in the age group of 20-30 years.

Most common clinical features observed were vomiting $(52.5 \%)$ and abdominal pain (41\%). These findings were comparable with Arunkumar ${ }^{6}$ et al \& Govindamurugan ${ }^{4}$ et al. 
Hypotension was found to be associated in 4 patients who consumed zinc phosphide. Some cases presented with bradycardia $(9.8 \%)$.

Many patients had hypoglycaemia (16.4\%) on presentation.

Prothrombin time abnormalities were increased in yellow phosphorus cases on presentation, but on the $4^{\text {th }}$ day, cases consumed bromadiolone were associated with increased prothrombin time abnormalities.

The incidence of hepatitis and jaundice were increased in those consumed yellow phosphorus and zinc phosphide, and the incidence increased further on the $4^{\text {th }}$ day.

\section{Outcome of yellow phosphorus}

Around $45 \%$ of thepatients experienced complications in our study.

All patients $(2.7 \%)$ who died were due to yellow phosphorus.

Fernandez and Canizares stated that in a series of 15 patients observed a mortality of $27 \%$ is recorded, confirming that Yellow Phosphorus is extremely lethal when ingested. ${ }^{7}$

\section{Outcome of zinc phosphide}

Around $43 \%$ of the patients experienced complications in our study.

No mortality was reported.

This is partly comparable to study by Shyam. P. lohani et $\mathrm{al}^{8}$, where $79 \%$ were asymptomatic, $20 \%$ had complications and only $1 \%$ died.

\section{Outcome in bromadiolones}

Most of the patients experienced only mild complications. No mortality reported. This is comparable to 8 year study by Litovitz TL Schmitz $^{9}$ et al, where a total of 79025 cases of superwarfarin exposure were studied, Out of which only 8 deaths were reported and only 67 patients $(0.08 \%)$ had major complications ${ }^{9}$.

\section{Tattoo and psychological correlation}

In our study, more than $50 \%$ of male patients had tattoos or self-inflicted wounds, compared to only a meagre of $6 \%$ of the female who had tattoos.
This indirectly shows the increased presence of maladjustment in males than in females. Around $78 \%$ of those tattooed or with self-inflicted wounds were diagnosed to have a psychiatric disorder.

\section{Conclusion}

The study concluded that most toxic rat killer poisons with high mortality were yellow phosphorus followed by zinc phosphide. Most common complication observed was acute hepatic failure followed by bleeding manifestations. Arrhythmias were common in zinc phosphide poisoning. The prognosis depends on the quantity consumed and the duration of presentation to hospital. Till now, no antidote has been devised yet to overcome the toxic effects of the poisoning and management is purely supportive care. Hence, strict medical policies should be implemented to restrict the availability and use of these chemicals. Interestingly, the association between tattooing and presences of psychiatric disturbance among the study population has been observed. This can be used as a tool to identify these groups of people and provide an additional psychiatric follow up and care for the better outcome.

\section{References}

1. Jeyaratnam J. Acute pesticide poisoning: a major global health problem. World Health Stat Q. 1990;43(3):139-44

2. Hettiarachchi J, Kodithuwakku GC. Pattern of poisoning in rural Sri Lanka. Int J Epidemiol. 1989 Jun;18(2):418-22.

3. Abdollahi M, Jalali N, Sabzevari O, Hoseini R, Ghanea T. A retrospective study of poisoning in Tehran. $\mathrm{J}$ Toxicol Clin Toxicol. 1997; 35(4): 387-93.

4. http://repositorytnmgrmu.ac.in/6050/1/200100513govinda _murugan.pdf

5. http://www.ijsrp.org/research-paper0815/ijsrp-p4442.pdf

6. http://repository-tnmgrmu.ac.in/6575/ 
7. Fernandez OU, Canizares LL. Acute hepatotoxicity from ingestion of yellow phosphorus-containing fireworks. J Clin Gastroenterol. 1995 Sep;21(2):139-42.

8. Shyam P. Lohani, Arjun Subedi, Acute Zinc Phosphide Poisoning in Nepal; Nepal Drug and Poison Information Center, Shamakhushi, Kathmandu.

9. Litovitz TL, Schmitz BF, Holm KC 1988 Annual report of the American Association of Poison Control Centers National Data Collection System. Am J Emerg Med. 1989;7495- 545. 